\title{
ANTIMICROBIAL ACTIVITY OF SOME THAI AROMATIC PLANTS AGAINST ORAL PATHOGENS INDUCING HALITOSIS
}

\author{
PLERNPIT YASIN ${ }^{1}$, PHENPHICHA WANACHANTARARUK ${ }^{2}$, JIDAPHATINOI ${ }^{1}$, KANCHANA DUMRI $^{1 *}$
}

${ }^{1}$ Department of Chemistry, Faculty of Science, Chiang Mai University, Chiang Mai, Thailand. ${ }^{2}$ Department of Faculty of Dentistry, Chiang Mai University, Chiang Mai, Thailand. Email: kanchana.d@cmu.ac.th

Received: 10 July 2018, Revised and Accepted: 07 December 2018

\section{ABSTRACT}

Objective: The objective of the present work is to analyze that the extracts of 25 Thai aromatic plants used in Thai food recipes were subjected to evaluated antimicrobial activity against Fusobacterium nucleatum and Streptococcus mutans which have been known as bacterial inducing halitosis.

Methods: Disk diffusion method, minimum inhibitory concentration (MIC), and minimum bactericidal concentration (MBC) by broth microdilution were used to determine the antibacterial activity.

Results: The results revealed that three plant extracts, namely Piper betle Linn., Eupatorium stoechadosmum Hance, and Alpinia galangal (L.) Wild can inhibit the growth of both halitosis inducing bacteria with strong activity. Among these, the extract of $P$. betle Linn. is the most effective in inhibiting both bacteria followed by E. stoechadosmum Hance and A. galangal (L.) Wild, respectively. The MIC (mg/ml) values of the extracts which can inhibit F. nucleatum were ranging from 1.56 to 12.50 , and the MBCs (mg/ml) values were ranging from 3.125 to 25.00 . In addition, the MICs and MBCs of the extracts which can inhibit $S$. mutans were found that 1.56-25.00 and 3.125-50.00, respectively.

Conclusion: The extracts obtained from P. betle, A. galangal, and E. stoechadosmum displayed good activity against F. nucleatum and S. mutans and these extracts could be a potential source of new antimicrobial agents.

Keywords: Antimicrobial activity, Thai aromatic plants, Fusobacterium nucleatum, Streptococcus mutans, Halitosis.

(C) 2019 The Authors. Published by Innovare Academic Sciences Pvt Ltd. This is an open access article under the CC BY license (http://creativecommons. org/licenses/by/4. 0/) DOI: http://dx.doi.org/10.22159/ajpcr.2019.v12i1.28404

\section{INTRODUCTION}

Halitosis, medically name of bad breath, or oral malodor, exhaled from the oral cavity. Halitosis is a significant social and psychological problem [9]. The intrinsic causes of halitosis are both oral cavity (90\%) and systemic disorder (10\%) [17]. Halitosis as the results of inadequate plaque control, tongue coating, periodontal disease, dental caries, oral candidiasis, oral infections, accumulation of food debris, and dry mouth [6]. The major compounds that cause halitosis are volatile sulfur compounds (VSCs) such as hydrogen sulfide and methyl mercaptan, which are produce from microbial metabolism of sulfur-containing amino acid. Fusobacterium nucleatum, Gram-negative anaerobic oral bacteria, has pathogenic potential and is implicated in periodontal diseases. It produces large amounts of VSCs and is a representative for the development of halitosis. On the other hand, bad breath has been reported to be caused by dental caries [13]. Dental caries causes acid formation by cariogenic bacteria such as $S$. mutans and results from the interaction of $S$. mutans and other related bacteria by production of biofilm on tooth surfaces [12].

Halitosis can be treated by mechanical and chemical methods. In addition, many products such as mouthwash, dentifrice, gum, tablets, and lozenges can play supporting roles in controlling oral malodor. Many methods can reduce halitosis by decrease microbial accumulation, nutrient availability, exerting anti-inflammatory, and masking the bad breath. The active ingredients used for controlling halitosis can be divided into chemical agents and naturally derived compounds. However, most chemical compounds have been known to induce side effects when prolong used. For example, chlorhexidine (CHX) stains the teeth and induces brownish discoloration of the pellicle covering teeth and tongue, alterations in test, increased desquamation of oral mucosa, and increase calculus formation [8]. To reduce the side effects of the chemical agents, the role of natural products may provide an alternative approach to develop new treatments. Aromatic plants are also known as herbs and spices and have been used since ancient times as folk medicine and as a preservative in foods. They contain many biologically active compounds which have been found to possess antimicrobial, antioxidant, and anti-inflammatory properties.

Nowadays, the demand for these plants has increased because they are natural, eco-friendly and generally believed to be safer than synthetic agents. Therefore, antimicrobial efficacies of aromatic plants synergistic with their aromatic effects are appreciable for halitosis neutralization and flavoring the oral care products as well [15]. Thailand is located in the tropical region, resulting in the variety of plants, including numerous species of aromatic plants. These plants are rich in various kinds of aromatic compounds. It is, therefore, interesting to investigate the effect of aroma compounds to inhibit microorganisms inducing halitosis. In this research is to evaluate the antimicrobial activity of some Thai aromatic plants traditionally used in Thai food recipes against $F$. nucleatum and S. mutans.

\section{MATERIALS AND METHODS}

\section{Plant materials}

Twenty-five Thai aromatic plants were purchased from a local market in Chiang Mai, Thailand. They were identified botanically at the Biology Department of Chiang Mai University, Chiang Mai, Thailand.

\section{Preparation of plant extract}

All of the fresh plants in this were cleaned and cut into small pieces before drying at $50^{\circ} \mathrm{C}$ in a hot air oven. At the end of drying, the final moisture content of dried plants determined by gravimetrically method was not exceeded $10 \%$ (dry basis). Dried plants were ground to get a fine powder using a mechanical blender and kept separately in plastic bags at room temperature before extraction. Dry plants were macerated 
with $80 \%$ ethanol [11] in the dark for 3 days at room temperature. At the end of extraction, each mixture was filtered using filter paper Whatman No.1 (Whatman International Ltd., Middlesex, England) and then was evaporated to dryness under reduced pressure in a vacuum rotary evaporator (Buchi Rotavapor R-114, Switzerland). The dried plant extracts were stored at $4^{\circ} \mathrm{C}$ in airtight sterile bottle, protected from light until used. The stock of plant extracts was dissolved in dimethyl sulfoxide (DMSO) to get $400 \mathrm{mg} / \mathrm{ml}$ concentration of each extract and used as a sample for determination of antimicrobial activity.

\section{Microorganisms and culture media}

The organisms used in this study were as followed: F. nucleatum (JMC 8532 or ATCC 10953) and S. mutans (ATCC 25175). These were kindly provided by the Japan Collection of Microorganisms, The Institute of Physical and Chemical Research (RIKEN), Japan and the laboratory of Department of Medical Science, Ministry of Public Health, Nonthaburi, Thailand, respectively. All media were purchased from Merck (Merck, Germany). Hemin and Vitamin K was purchased from Remel (Remel, Lenexa, KS).

\section{Antimicrobial assay}

\section{Disk diffusion method}

Antimicrobial activity was determined by agar disk diffusion method [5]. Fusonucleatum nucleatum was cultured in brain heart infusion (BHI) broth supplemented with 1.0\% (v/v) hemin and $0.1 \%$ (v/v) Vitamin $\mathrm{K}$ for $72 \mathrm{~h}$ at $37^{\circ} \mathrm{C}$ under anaerobic condition $\left(10 \% \mathrm{H}_{2}\right.$, $10 \% \mathrm{CO}_{2}$, and $80 \% \mathrm{~N}_{2}$ ). The inoculum suspension was prepared which adjusted their turbidity to $1.0 \times 10^{8} \mathrm{CFU} / \mathrm{ml}$ equivalent to McFarland standard No. 0.5 [19]. Each of inoculum suspension was prepared freshly before use, spread on the surface of agar using a sterile cotton swab moistened with inoculum suspension. Blood agar plate containing hemin and Vitamin $\mathrm{K}$ was used for $F$. nucleatum. A $\varnothing 6 \mathrm{~mm}$ diameter sterile paper discs (Whatman International Ltd., Middlesex, England) were loaded with $20 \mu \mathrm{l}(400 \mathrm{mg} / \mathrm{ml})$ of plant extract, allowed to dry and placed on the agar surface. Plates were then incubated at $37^{\circ} \mathrm{C}$ for $72 \mathrm{~h}$ under anaerobic condition.
$S$. mutans was grown in BHI broth at $37^{\circ} \mathrm{C}$ for $24 \mathrm{~h}$ under anaerobic condition and adjusted their turbidity to $1.0 \times 10^{8} \mathrm{CFU} / \mathrm{ml}$. The processes were the same as mentioned above except instead of using BHI plate were incubated at $37^{\circ} \mathrm{C}$ for $24 \mathrm{~h}$ under anaerobic condition. A $0.12 \% \mathrm{CHX}$ and DMSO were used as negative controls and positive control, respectively.

After incubation, the antimicrobial activity of plant extract was determined by measuring the diameter of the inhibition zone in millimeter. All experiments were done in triplicates.

\section{Minimum inhibition concentration (MIC)}

After completion of MIC determination, the MIC results of this experiment were confirmed by minimum bactericidal concentration (MBC) determination. The MBC can be determined by subculturing [4]. One loop full of a sample from each well was transferred on an agar plate and further incubation at $37^{\circ} \mathrm{C}$ under anaerobic condition for $72 \mathrm{~h}$ and $24 \mathrm{~h}$ for $F$. nucleatum and $S$. mutans, respectively. The MBC value was recorded as the lowest concentration of plant extract that killed bacteria after incubation.

\section{Statistical analysis}

Data were expressed as mean and standard deviation by computational analysis from three independent experiments.

\section{RESULTS}

At present, the demand for natural substances is increasing because it is more secure than synthetic materials. Therefore, the search for plants that inhibit bacteria causing bad breath is considered to be interesting research. In the present study, 25 Thai aromatic edible plant extracts were evaluated for their antimicrobial activity against halitosis inducing bacteria ( $F$. nucleatum and $S$. mutans). The antimicrobial activity of the extracts and their potency was accessed by the presence and absence of the inhibition zone and zone diameter, respectively, as given in Table 1. Only the alcoholic extract evaluated, as alcohol was found to be a better

Table 1: Antimicrobial activity of Thai aromatic plant extracts against $F$. nucleatum, $S$. mutan using agar disk diffusion method

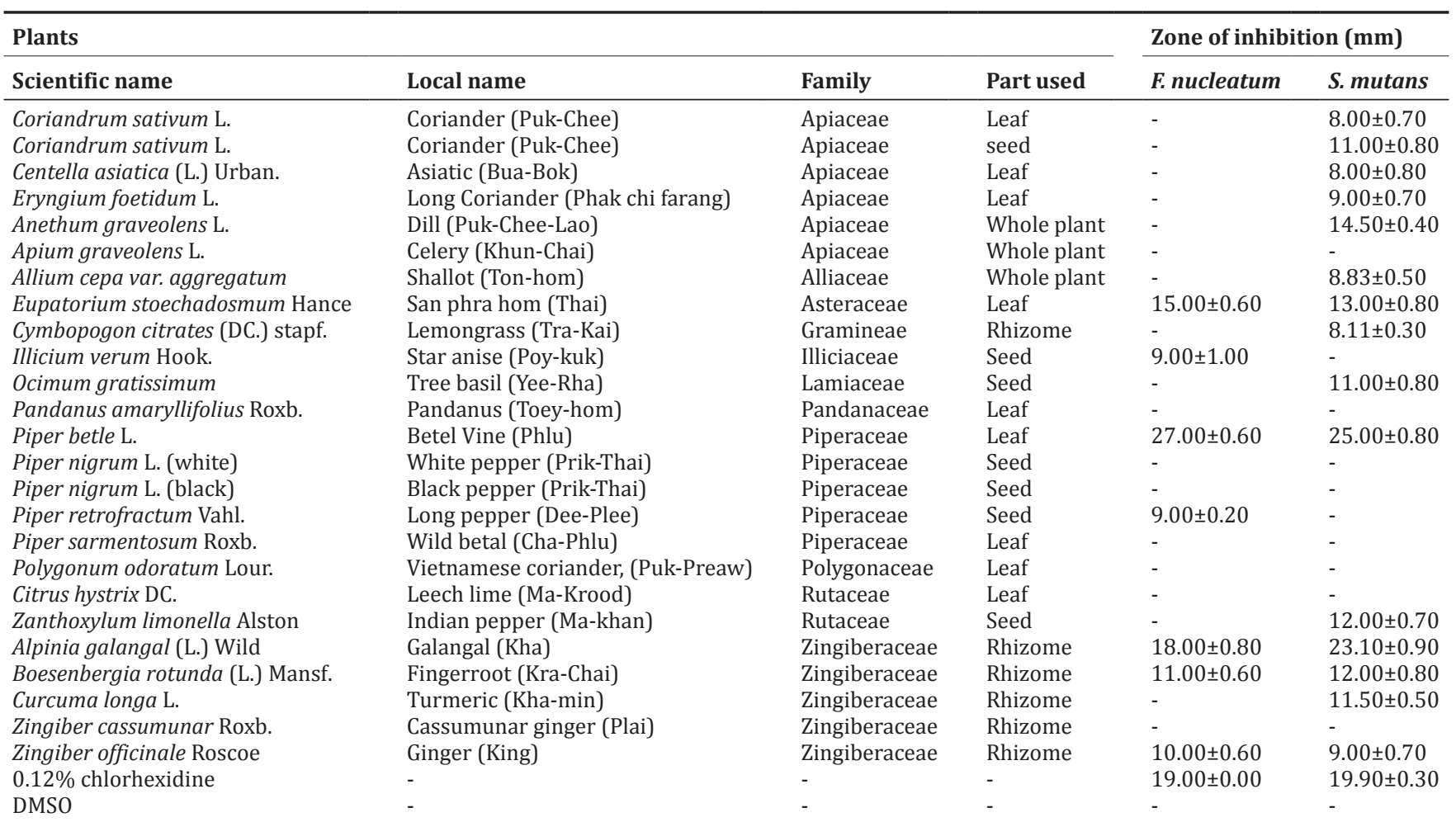

Remarks: Values for the zone of growth inhibition (mm) are presented as mean of triplicates \pm SD. Interpretation of the plant extracts activity; (-): No inhibition zone, none activity $\leq 8 \mathrm{~mm}, 9-11 \mathrm{~mm}$ intermediate activity and $\geq 12 \mathrm{~mm}$ strong activity (Bauer et al., 1966) DMSO: Dimethyl sulfoxide, SD: Standard deviation 
solvent for extraction of active substances with having antimicrobial activity when compared to water and hexane [1]. In this experiment, the reference standards $0.12 \%$ CHX disc showed inhibitory activity against both types of tested bacteria. The DMSO was used as negative control and did not show any activity. The 14 extracts from 25 plants were effective against 1 or 2 tested bacteria. The results showed that seven extracts could effectively inhibit the growth of $F$. nucleatum with the inhibition zone ranging from 27.00 to $9.00 \mathrm{~mm}$. The 12 extracts showed inhibitory activity against $S$. mutans with the inhibition zone ranging from 8.11 to $25.00 \mathrm{~mm}$. In addition, the results also show that there are five extracts that are effective against both types of bacteria. Among these plants, Piper betle Linn., Eupatorium stoechadosmum Hance, and Alpinia galangal (L.) Wild have a strong activity against both types of bacteria. The remaining nine plants had none activity on both types of tested bacteria. Subsequently, the plant extracts that showed inhibitory activity against one or both bacteria was conducted to determine MICs and MBCs. The results are summarized in Table 2. For plant extracts that can inhibit the growth of both bacteria with strong activity revealed that $P$. betle Linn. is most effective in inhibiting both of bacteria followed by E. stoechadosmum Hance and A. galanga (L.) Wild, respectively. The MIC $(\mathrm{mg} / \mathrm{ml})$ values of the extracts which can inhibit F. nucleatum were ranging from 1.56 to 6.25 , and the MBCs were ranging from 3.125 to $12.50(\mathrm{mg} / \mathrm{ml})$. In addition, the MICs and MBCs of the extracts which can inhibit $S$. mutans were found that 1.56-25.00 and $3.125-50.00(\mathrm{mg} / \mathrm{ml})$, respectively. Selective plant extracts will be further carried out for purification and possibility for alternative oral care product.

\section{DISCUSSION}

In this study, the antimicrobial activity of 25 Thai aromatic plant extracts against oral pathogens (F. nucleatum and S. mutans) inducing bad breath. In the study, DMSO and the $0.12 \%$ CHX discs were used as negative and positive control, respectively. DMSO without any plant extracts was used as negative control, and none activity could detect for all of the tested bacteria. DMSO consists of a polar part and two nonpolar parts that provide its able to solubilize polar and nonpolar substances and

Table 2: The MIC and MBC of Thai aromatic plant extracts using broth microdilution

\begin{tabular}{|c|c|c|c|c|}
\hline \multirow[t]{2}{*}{ Plant extracts } & \multicolumn{2}{|c|}{ F. nucleatum } & \multicolumn{2}{|c|}{ S. mutans } \\
\hline & MIC & MBC & MIC & MBC \\
\hline Coriandrum sativum L. (leave) & $>200$ & $>200$ & 50 & 100 \\
\hline Coriandrum sativum L. (seed) & $>200$ & $>200$ & 50 & 100 \\
\hline Centella asiatica (L.) Urban & $>200$ & $>200$ & 100 & 200 \\
\hline Eryngium foetidum L. & $>200$ & $>200$ & 50 & 100 \\
\hline Anethum graveolens Linn. & $>200$ & $>200$ & $>200$ & $>200$ \\
\hline Apium graveolens L. & $>200$ & $>200$ & 12.50 & 25.00 \\
\hline Allium cepa var. aggregatum & $>200$ & $>200$ & 50 & 100 \\
\hline Eupatorium stoechadosmum Hance & 6.25 & 12.50 & 6.25 & 12.5 \\
\hline Cymbopogon citratus Stapf. & $>200$ & $>200$ & $>200$ & $>200$ \\
\hline Illicium verum Hook. & $>200$ & $>200$ & 25.00 & 50.00 \\
\hline Ocimum gratissimum & $>200$ & $>200$ & 50 & 100 \\
\hline Pandanus amaryllifolius Roxb. & $>200$ & $>200$ & $>200$ & $>200$ \\
\hline Piper betle Linn. & 1.56 & 3.125 & 1.56 & 3.125 \\
\hline Piper nigrum L. (white) & $>200$ & $>200$ & $>200$ & $>200$ \\
\hline Piper nigrum L. (black) & $>200$ & $>200$ & $>200$ & $>200$ \\
\hline Piper retrofractum Vahl. & $>200$ & $>200$ & $>200$ & $>200$ \\
\hline Piper sarmentosum Roxb. & $>200$ & $>200$ & $>200$ & $>200$ \\
\hline Polygonum odoratum Lour. & $>200$ & $>200$ & $>200$ & $>200$ \\
\hline Citrus hystrix DC & $>200$ & $>200$ & $>200$ & $>200$ \\
\hline Zanthoxylum limonella Alston & $>200$ & $>200$ & 25 & 50 \\
\hline Alpinia galangal (L.) Wild & 6.25 & 12.50 & 25.00 & 50.00 \\
\hline Boesenbergia rotunda (L.) Mansf. & 12.50 & 25.00 & 50.00 & 100.00 \\
\hline Curcuma longa $\mathrm{L}$. & $>200$ & $>200$ & 50 & 100 \\
\hline Zingiber cassumunar Roxb. & $>200$ & $>200$ & $>200$ & $>200$ \\
\hline Zingiber officinale Roscoe & 12.50 & 25.00 & 25.00 & 50.00 \\
\hline
\end{tabular}

MIC: Minimum inhibitory concentration, MBC: Minimum bactericidal concentration transpose across hydrophobic barriers. These properties are important for vehicle pharmacological compound that acts in intracellular (Lucas et al., 2017). The $0.12 \%$ CHX is an antimicrobial agent. Its antimicrobial action of CHX is due to a positively-charged molecule that binds to the negatively-charged of phospholipids in the inner membrane, leading to increased permeability of the inner membrane and leakage of cell components, such as potassium ions which leading to cell death [10].

The results of this experiment clearly showed that the crude extracts of three plants, namely P. betle Linn., E. stoechadosmum Hance, and A. galangal (L.) Wild revealed a strong inhibitory activity against both of tested bacteria. The results of this experiment are agree with the other reports which related the activity of $P$. betle and A. galanga. Among these reports, Deshpande et al. (2013) [20] and Dinesh et al. (2016) [21], who showed that the ethanol extracts of Piper betel leaves had inhibitory activities against $S$. mutans. The effects of $P$. betle on $F$. nucleatum were found to be consistent with the report of Ramji et al. (2002) [16] and Babitha et al. (2017) [3]. Similar reports on the antimicrobial activity of $A$. galanga extracts, in this study, were found to be consistent with the report of Teanpaisan et al. (2016) [18] who finding that the ethanolic extract of $A$. galangal has inhibitory activity against both of bacteria. However, the effectiveness of active plant extracts in this study was found to be different from that reported in other studies. This may be due to many factors such as chemical constituents in the extract, vegetative period of the plant (before or after flowering), and environmental factors such as the geo-climatic location and growing conditions, including the concentration of nutrients, temperature, humidity, soil type, and amount of available water [2].

The antibacterial activity of ethanolic leaves extract from E. stoechadosmum Hance against $F$. nucleatum and $S$. mutans has not been reported. The bacterial inhibitory properties of this plant may be attributed to the active constituents. Studies on the constituents of this plant have been reported by Dung et al. (1991) [7]. In the report, found that the major constituents of essential oil from $E$. stoechadosmum Hance contained thymohydroquinone dimethyl ether (73.6\%), caryophyllene $(8.9 \%)$ and selina-4,11-diene (11\%). Therefore, the study of the chemical constituents of this plant that effects the bacteria are interesting to continue studying.

\section{CONCLUSION}

In this study demonstrated that extracts obtained from $P$. betle, A. galanga, and E. stoechadosmum Hance displayed good activity against F. nucleatum and $S$. mutans. These plant extracts could be a potential source of new antimicrobial agents. For further study, selective plant extracts will be carried out for purification and possibility useful for alternative oral care product.

\section{ACKNOWLEDGMENT}

This work was in part supported by the fund from Chandrakasem Rajabhat University, Thailand.

\section{AUTHOR(S) CONTRIBUTIONS}

All the authors contributed equally to this manuscript.

\section{CONFLICTS OF INTEREST}

Declared none.

\section{REFERENCES}

1. Ahmad I, Mehmood Z, Mohammad F. Screening of some Indian medicinal plants for their antimicrobial properties. J Ethnopharmacol 1998;62:183-93

2. Aleksic V, Knezevic P. Antimicrobial and antioxidative activity of extracts and essential oils of Myrtus communis L. Microbiol Res 2014; 169:240-54.

3. Babitha GA, Ansu KP, Shobha P, Shiva C, Thimma S, Kishore B. Betle Leaf-a Pathogen's engima. Int J Curr Res 2017;9:53229-31. 
4. Balouiri M, Sadiki M, Ibnsouda SK. Methods for in vitro evaluating antimicrobial activity: A review. J Pharm Anal 2016;6:71-9.

5. Bauer AW, Kirby WM, Sherris JC, Turck M. Antibiotic susceptibility testing by a standardized single disk method. Am J Clin Pathol 1966;45:493-6.

6. Cortelli JR, Barbosa MD, Westphal MA. Halitosis: A review of associated factors and therapeutic approach. Braz Oral Res 2008;22 Suppl 1:44-54.

7. Dung XN, Tarn TN, Kruk C, Leclercq AP. Composition of the oil of Eupatorium stoechadosmum Hance from Vietnam. J Essent Oil Res 1991;3:115-6

8. Gagari E, Kabani S. Adverse effects of mouthwash use. A review. Oral Surg Oral Med Oral Pathol Oral Radiol Endod 1995;80:432-9.

9. Greenberg M, Urnezis P, Tian M. Compressed mints and chewing gum containing magnolia bark extract are effective against bacteria responsible for oral malodor. J Agric Food Chem 2007;55:9465-9.

10. Gurbani K, Archana S, Kaustubh PP, Gopalakrishnan D, Abhishek S, Sachin D. Chlorhexidine: First to be known, still a gold standard antiplaque agent. Res J Pharm Biol Chem Sci 2015;6:1407-24.

11. Handa SS, Khanuja SP, Longo G, Rakesh DD. Extraction Technologies for Medicinal and Aromatic Plants, No 66. $1^{\text {st }}$ ed. Italy: United Nations Industrial Development Organization and the International Centre for Science and High Technology; 2008. p. 21-22.

12. Lamont RJ, Demuth DR, Davis CA, Malamud D, Rosan B. Salivaryagglutinin-mediated adherence of Streptococcus mutans to early plaque bacteria. Infect Immun 1991;59:3446-50.

13. Lewis DW, Ismail AI. Periodic health examination, 1995 update: 2. Prevention of dental caries. The Canadian task force on the periodic health examination. CMAJ 1995;152:836-46.

14. de Abreu Costa L, Henrique Fernandes Ottoni M, Dos Santos MG,
Meireles AB, Gomes de Almeida V, de Fátima Pereira W, et al. Dimethyl sulfoxide (DMSO) decreases cell proliferation and TNF- $\alpha$, IFN- $\gamma$, and IL-2 cytokines production in cultures of peripheral blood lymphocytes. Molecules 2017;22:1-10.

15. Lourith N, Kanlayavattanakul M. Oral malodour and active ingredients for treatment. Int J Cosmet Sci 2010;32:321-9.

16. Ramji N, Ramji N, Iyer R, Chandrasekaran S. Phenolic antibacterials from Piper betle in the prevention of halitosis. J Ethnopharmacol 2002;83:149-52.

17. Rosenberg M. The science of bad breath. Sci Am 2002;286:72-9.

18. Teanpaisan R, Kawsud P, Pahumunto N, Puripattanavong J. Screening for antibacterial and antibiofilm activity in Thai medicinal plant extracts against oral microorganisms. J Tradit Complement Med 2017;7:172-7.

19. Zaidan MR, Noor Rain A, Badrul AR, Adlin A, Norazah A, Zakiah I, et al. In vitro screening of five local medicinal plants for antibacterial activity using disc diffusion method. Trop Biomed 2005;22:165-70.

20. Deshpande SN, Kadam DG. GCMS analysis and antibacterial activity of Piper betle (Linn) leaves against Streptococcus mutans. Asian J Pharm Clin Res 2013;6:99-101

21. Dinesh MD, Anjana JC, Neethu G, Nithya J, Sharannya M, Meenatchisundaram S. Anti-cariogenic activity of piper betel leaf extracts against Streptococcus mutans and Streptococcus oralis by in vitro. Quest J 2016;3:50-4.

22. Da Silva LI, Karuppusamy A, Miyajima F, Violante IM, Bieski IG, Balogun SO, De Oliveira Martins DT. Antimicrobial and antioxidant activities of selected plants used by populations from Juruena valley, legal amazon, Brazil. Int J Pharm Pharm Sci 2017;9:179-91.

23. Lavanya J, Selvam SP, Priya MJ, Jacintha P, Aradana M. Antioxidant and antimicrobial activity of selected medicinal plants against human oral pathogens. Int J Pharm Pharm Sci 2016;8:71-8. 